\title{
Guard lines conformal slotted antenna array for multiband application
}

\author{
Brajlata Chauhan ${ }^{1}$, Suresh Chandra Gupta ${ }^{2}$, Sandip Vijay ${ }^{3}$ \\ ${ }^{1,2}$ Department of Electrical and Electronics Engineering, DIT University Dehradun, Uttrakhand, India \\ ${ }^{3}$ Department of ECE, Shivalik College of Engineering, Dehradun, Uttrakhand, India
}

\begin{abstract}
Article Info
Article history:

Received Jun 19, 2020

Revised Jul 12, 2020

Accepted Mar 25, 2021

Keywords:

Corporate feed

Cross polarization

Cst software

Guard line

Microstrip conformal antenna

Multiple band

ABSTRACT

This work investigated a for a miniaturized slotted conformal antenna array for multiband application. Three guard lines are incorporated to the side of main patch and top of main patch to reduce surface current for planner surface and observe the effect of guard line due to which it resonate at three frequencies in $\mathrm{X}$ band and $\mathrm{Ku}$ band to be useful for multiband. A rectangular slot is etched at center of patches to increase the current path for wide band application. A quarter wave length feeding network is used with good agreement of impedance matching. The main lobe width and direction shows through the radiation pattern which remains stable even it is significantly curved. This structure is wrapped around a cylinder with diameter of 41.4 $\mathrm{mm}$ in circumferential direction. It is observed that the planner antenna array operating at $8.4 \mathrm{GHz}, 11.2 \mathrm{GHz} \& 18.2 \mathrm{GHz}$ with return loss of $-20 \mathrm{~dB}$ to $-45 \mathrm{~dB}$ with fractional $\mathrm{BW}$ of $25 \%$ at 3rd frequency range and the directivity from $3.4 \mathrm{dBi}-6.8 \mathrm{dBi}$. By doing some alteration in dimensions for the conformal antenna producing fractional BW of $20 \%$ and the directivity 5.5 to $9.1 \mathrm{dBi}$ at resonating frequencies of $8.4 \mathrm{GHz}, 11.4 \mathrm{GHz}$ and $17.5 \mathrm{GHz}$. This proposed array is simulated on CST software.
\end{abstract}

This is an open access article under the CC BY-SA license.

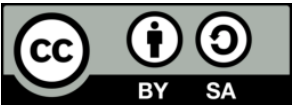

\section{Corresponding Author:}

Brajlata Chauhan

Department of Electrical Electronics and Communication

DIT University

Dehradun, Uttrakhand India

Email: braj.lata@rediffmail.com

\section{INTRODUCTION}

In last one decade researchers paid lot of attention towards antenna for better performance and versatile features. Planner antenna, which we can't use for all purpose, hence conformal antenna was proposed. A modern antenna, which can conforms to any prescribed shape like a high speed train, a space suite, a car, a part of missiles, some part of a media van, an aero-plane, fast moving trains, or other vehicles. The aim is to develop miniaturized conformal antenna so that it could be integrated with the structures with useful applications.

A conformal antenna can be almost in any shape like cylindrical, spherical and conical or in other shapes also, in which the antenna elements are integrated or mounted onto the smoothly curved surface. A 4elements conformal antenna array investigated for cylindrical surface and analyze the effect of mutual coupling [1], [2]. When MSA printed on curved surface, the radiation characteristics or desired output will be degrade as compared to planer surface. This non-planner surface of MSA may print on the flexible, semi flexible and thin substrate. so that it can be mounted on curve surface, such antenna system can be developed to operated under such conditions, either the antenna parameter of the curved surface is acceptable for the 
required application or it has to compensate the degrade antenna performance using the compensating circuit/components. Thus, implementation of the microstrip antenna array to the curved surface may be the solution for different application as civil or military air crafts, vehicles, and wearable application. The technique used to analyze microstrip antenna for non planar surface conforming to the parent structure as cylinder has been explained. A flexible miniaturized bowtie antenna proposed at 2.4 GHZ. [3]-[8].

Narrow bandwidth is a major limitation of planar MSA. To resolve it different methods have been developed for bandwidth enhancement of an antenna. They are as: slot loaded patch, modifying the feed, shorting pin, using DGS, parasitic patch and multilayer resonator. To enhance the bandwidth of a patch, cut a slot in the patch of half wavelength long at desired frequency. These slots are in different shapes as E, H, U. There is no analytical approach is developed to compute the exact dimensions of the slot, but a half wavelength long slot provides good agreement to compare the length of slot at desired resonance. A probe feeding, the impedance bandwidth of 2.0-6.3 GHz at resonating frequency of $4.2 \mathrm{GHz}$ has been obtained with the return loss of $-30 \mathrm{~dB}$ and VSWR of less than 1.07 [9]. The bandwidth of antenna can be improved by use of parasitic elements, by introducing two capacitance technique to excite the parasitic element placed parallel to the radiating edges, creating broadband $\mathrm{U}, \mathrm{E}, \mathrm{T}$ and $\mathrm{H}$ shape slot electromagnetic coupling probe feeding technique [10]-[13]. A "MIMO" antenna presented with improved isolation and impedance matching at $6 \mathrm{GHz}$ and a Multi band application proposed with a hexagonal complementary split ring resonator. A reconfigurable antenna using PIN diode proposed with harmonic suppression [14]-[16]. An optimal conformal antenna array structure for DOA (direction-of-arrival) estimation on the planar surface and then conforming it on a cylindrical and hemispherical surface studied using the directive elements. Results concluded by adopting different algorithms as CR (Cramer-Rao) lower bound, multiple signal classification, and rms error algorithms to evaluate the estimation accuracy of the conformal antennas [7].

\section{SLOTTED CYLINDERICAL CONFORMAL ANTENNA}

A wrap around technique introduced antenna placed on cylindrical shape surface and then it provide radial omni pattern with nulls at axis [17]. A folded slot conformal antenna array investigated using two elements with coplanar waveguide [5]. The enhancement in bandwidth and miniaturization of Patch may be achieved by etching the slot in ground and the proper dimensions of patch of Microstrip antenna. The longest slot length provides the minimum change in the resonance frequency whereas maximum change for the minimum slot length. Many literatures have been reported for the slot antenna. Here, that slotted antenna applied for conformal application on cylinder. A comparative performance analysis has been made for these slots shape as: $\pi$ and half $\pi, U$ and half $U$ slots design are proposed and reduced area to 50\%. [1], [2], [18][20]. A conformal structure with truncated corner used for circular polarization. This work presents a slotted conformal antenna by incorporating two slots E shape and $U$ shape which is back-to-back connected to each other and observed the effect of length, width \& height on $S_{11}$, radiation pattern and shifting in frequency. It is fabricated using epoxy FR4 substrate [5], [21], [22].

\subsection{Single layer curved surface conformal antennas}

The separately bended surface antenna is the least complex type of conformal antenna. The fundamental goal of such antenna is to improve the azimuthally inclusion or acquiring omni-directional coverage at times. The roundabout tube shaped antenna is usually utilized structure in conformal reception apparatuses for various applications. The conical form of antenna is also singly curved surface for particular applications in the cockpit of aircraft or missiles [19], [23], [24]. Here, in this section only cylindrical antennas will be considered because of their simple geometry. The change of the resonant frequency with change in curvature of cylindrical surface taken into account, as show in Figure 1. It is also considered for the full wave analysis. The resonant frequency for a patch for mnth TM mode to be determined analytically as (1) and (2).

$$
\begin{aligned}
& E_{p}=E_{0} \cos \left[\frac{m \pi}{2 \theta}\left(\varphi-\varphi_{1}\right)\right] \cos \left(\frac{n \pi z}{2 b}\right) \\
& f_{m n}=\frac{c}{2 \sqrt{\varepsilon_{r}}}\left[\left\{\frac{m \pi}{2 a \theta_{1}}\right\}^{2}+\left\{\frac{n \pi}{2 b}\right\}^{2}\right]^{1 / 2}
\end{aligned}
$$

For rectangular patch antenna with $[\mathrm{R}=$ a] radius cylindrical ground plane, Straight edge length $=2 b$, Arc or curved length $=2(a+h) \theta_{1}$ 


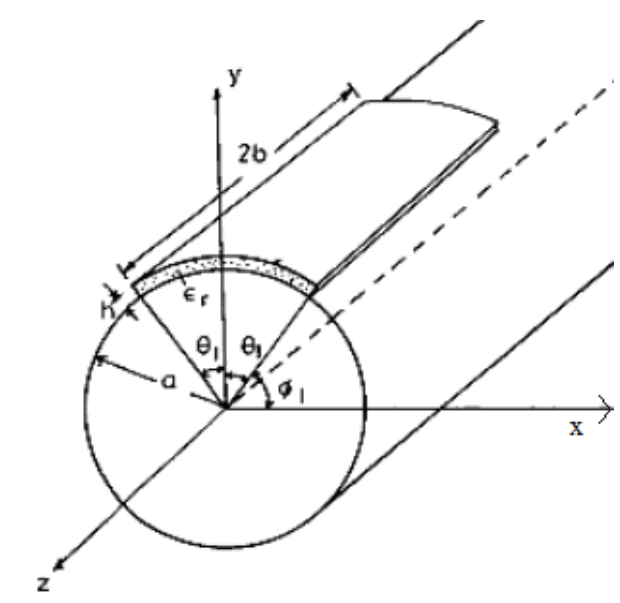

Figure 1. Rectangular microstrip patch on the cylindrical surface

$$
f_{m n}=\frac{c}{2 \sqrt{\varepsilon_{r}}} \sqrt{\left(\frac{m}{W}\right)^{2}+}\left(\frac{n}{L}\right)^{2}
$$

Where $W=2 R \emptyset_{0}+t / \sqrt{\varepsilon_{r}}$

Is the effective circumferential length of the patch and

$L=Z_{m}+t / \sqrt{\varepsilon_{r}}$ is theeeffective axial length

$Z_{m}$ is the axial length of the patch

$2 R \emptyset_{0}$ and $Z_{m}$ is the actual dimensions of the patch with ' $R$ ' as the radius of cylinder

$\emptyset_{0}$ is the angle from the center of patch to the straight edge

\section{EFFECT OF CURVATURE ON CONFORMAL PATCH}

To determine the basic dimension of the patch, section 3.3 reported all the related (6). The single antenna is a printed on the $21 \mathrm{~mm} \times 51 \mathrm{~mm}$ patch grounded FR4 dielectric substrate with the dielectric constant of 4.3 and substrate height $(\mathrm{h})=2.5 \mathrm{~mm}, f_{r}=$ in between $10-18 \mathrm{GHz}$, Radius $r_{1}=35 \mathrm{~mm}$. The dimensions (L $\& \mathrm{~W}$ ) of the antenna may calculate using transmission line method. The conductor thickness taken as chosen is $4.7 \mu \mathrm{m}$. To find the axial length $\mathrm{L}$, determine the angle subtended by measuring two axial lines of patch passing through centre of cylinder to the patch edge shown in Figure 1.

$$
L=\frac{\varphi}{180} \times \pi \times \text { radius, } W=1_{2} \varphi_{m m}
$$

The transmission line method is applicable to infinite ground planes only. For the practical considerations for the line calculation, it is necessary to have a finite ground plane of antenna. The results for infinite and finite ground plane may be optimize if the size of the ground plane is larger than the antenna patch dimensions by approximately six times of the substrate thickness overall.

\section{DIMENSIONS OF SLOTTED PLANNER AND CONFORMAL ANTENNA ARRAY}

Antenna model dimension in $\mathrm{mm}$ as shown in Table 1 . The factors affecting the bandwidth of a MSA are shape of the radiator, the substrate, the feeding scheme and the arrangements of slot, radiating and parasitic elements. A wide bandwidth of a MSA may be attributed to its low Quality factor and simultaneously provides well excited multiple resonances. Bandwidth enhancement using slot loading technique, a quarter wave length with width of $0.12 \mathrm{~mm}$ slot is created on the radiating patch of antenna 
which leads to wide bandwidth due to double resonant effect while keeping the size small [18]. The slot in the patch increases the current path length and thus increases bandwidth.

The guard line dimensions are: $\mathrm{Lg}_{\mathrm{L} 1}=\mathrm{Lg}_{\mathrm{L} 2}=6.2 \mathrm{~mm}, \mathrm{Lg}_{\mathrm{L} 3}=8.4 \mathrm{~mm}, \mathrm{Wg}_{\mathrm{L}}=1.2 \mathrm{~mm}$.

Table 1. Antenna model dimension in $\mathrm{mm}$

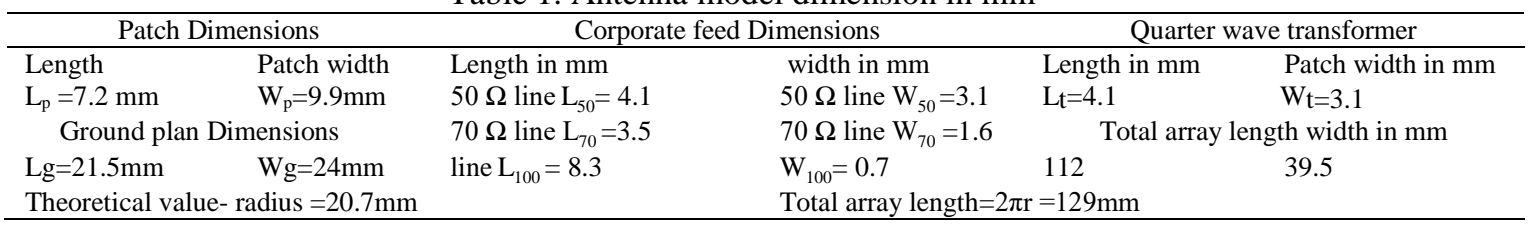

A slotted array for above structure resonating at $\mathrm{X}$ and $\mathrm{Ku}$ band is given in Figure 2. A single element slot antenna presented with centre slot in Order to achieve greater bandwidth with the suitable gain as the gain and bandwidth product is constant. The scattering result of single element resonating at four frequency at $7.3 \mathrm{Ghz}, 11.5 \mathrm{Ghz}, 14.5 \mathrm{GHz}$ and $19.16 \mathrm{Ghz}$ with the return losses of $-11.3 \mathrm{~dB},-11.57 \mathrm{~dB},-15.68$ and $-23.7 \mathrm{~dB}$ respectively and producing $-10 \mathrm{~dB}$ bandwidth of $2.44 \mathrm{GHz}$. But the gain of this single element antenna is little bit low about $1.8-4.2 \mathrm{~dB}$ at above frequencies. In order to increase the gain of antenna, a four element has introduced here.
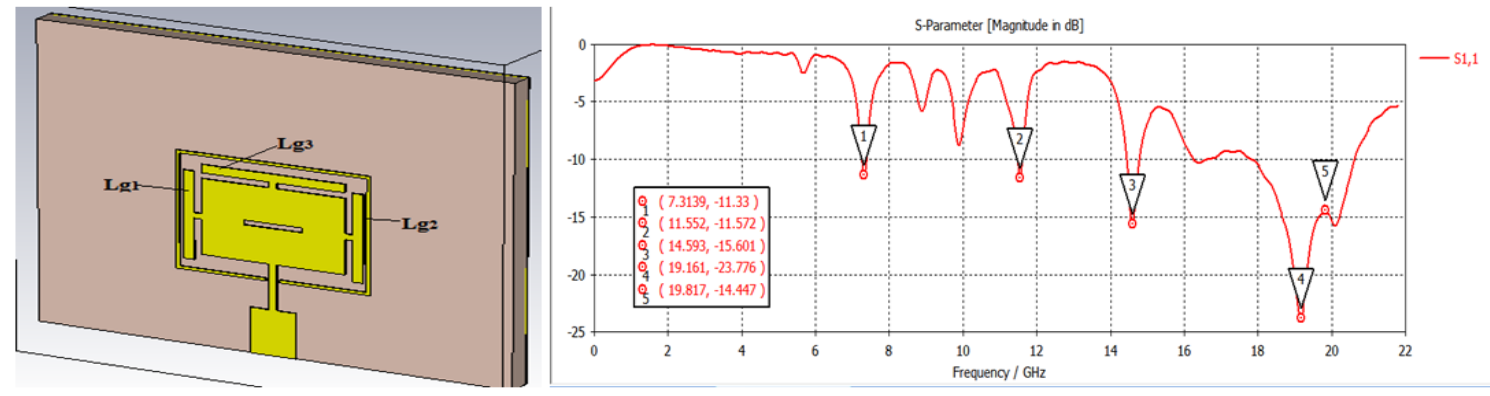

Figure 2. Model and $\mathrm{S}_{11}$ in $\mathrm{dB}$ for centre slot single element antenna

\section{RESULT ANALYSIS - PROPOSED PLANAR AND CONFORMAL SLOTTED ANTENNA}

This antenna array makes a tradeoff between gain and resonating frequencies. My previous work done and above analysis prove that the antenna array characteristics parameters as direction of radiation pattern, gain, directivity, shifting in frequency, bandwidth and angular width are affected after conforming the same planar structure[1]-[3] as show in Figure 3. It observed from this analysis that radiation characteristic degrades and with increase in radius, frequency and return loss decreases [1], [2]. In the conformal structure, resonating frequencies has been shifted slightly due to the change in length of curve surface. As conforming the surface gain get reduces.
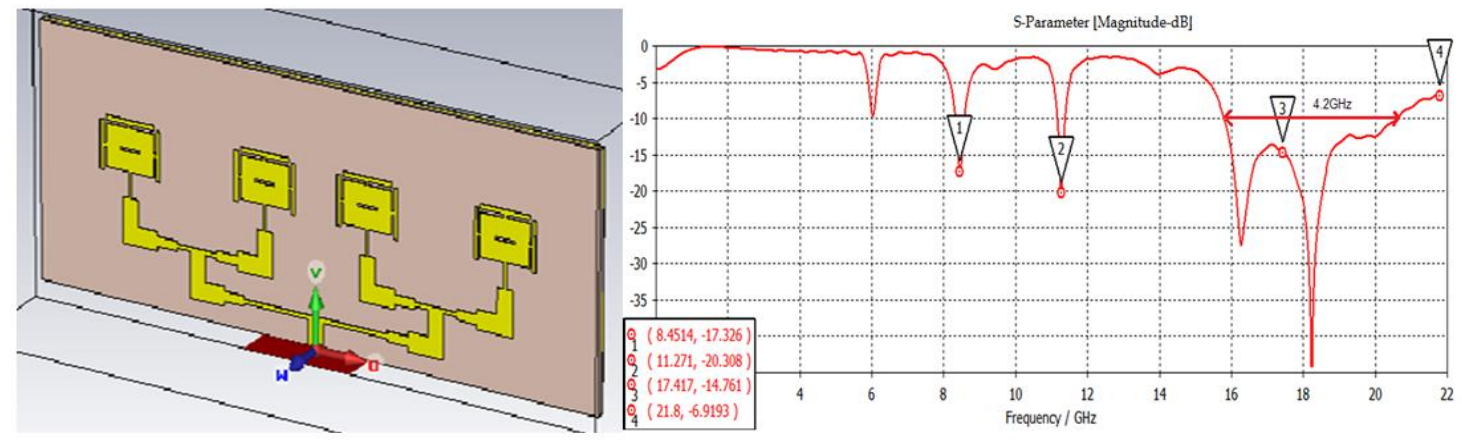

Figure 3. Model and S11-parameter centre slot four element planar array on CST plate form 
Return losses for planar array is $-45 \mathrm{~dB}$ at $18.1 \mathrm{GHz}$ and $-10 \mathrm{~dB}$ bandwidth is $4.35 \mathrm{GHz}$ and fractional bandwidth is given $\mathrm{f}_{\mathrm{c}}=\left(\mathrm{f}_{1}+\mathrm{f}_{2}\right) / 2=18.2$. A wide band application have $20 \%$ or greater $\mathrm{BW}$ and $>50 \%$ for ultra wide band.

\section{$\left(f_{2}-f_{1}\right) / f c \times 100=(20.5-15.9) / 18.2 \times 100=25.2 \%$}

Some iteration has been done in order to maintain the similar result as achieved in planar configuration. By reducing the side guard line length from $8.4 \mathrm{~mm}$ to $8.1 \mathrm{~mm}$ and increased the height of substrate, frequency shifted ahead whereas frequencies will be shifted before for the conformal array antenna. So that similar resonating frequencies may be maintained. This shifting is caused by the change in length of curve surface. By which length will increases and frequencies shifted before the previous one. Optimization techniques used to achieve good agreement of results. As a result overall performances have been improved with the tradeoff of gain and bandwidth shown in Figure 4.

In the previous work already proposed, radiation pattern get shifted in another direction with different angular width $10^{0}-90^{0}$ for the cylindrical application [1[, [2], [5], [6], [18], [20], [22], [25]. This shifting of beam or radiation pattern may get back to its original position by phase shifting networks in the conformal structure. In the given proposed conformal antenna radiation pattern also get shifted by $30^{\circ}-45^{\circ}$. That may overcome using meandering in the feeding network and diode as phase shifter.
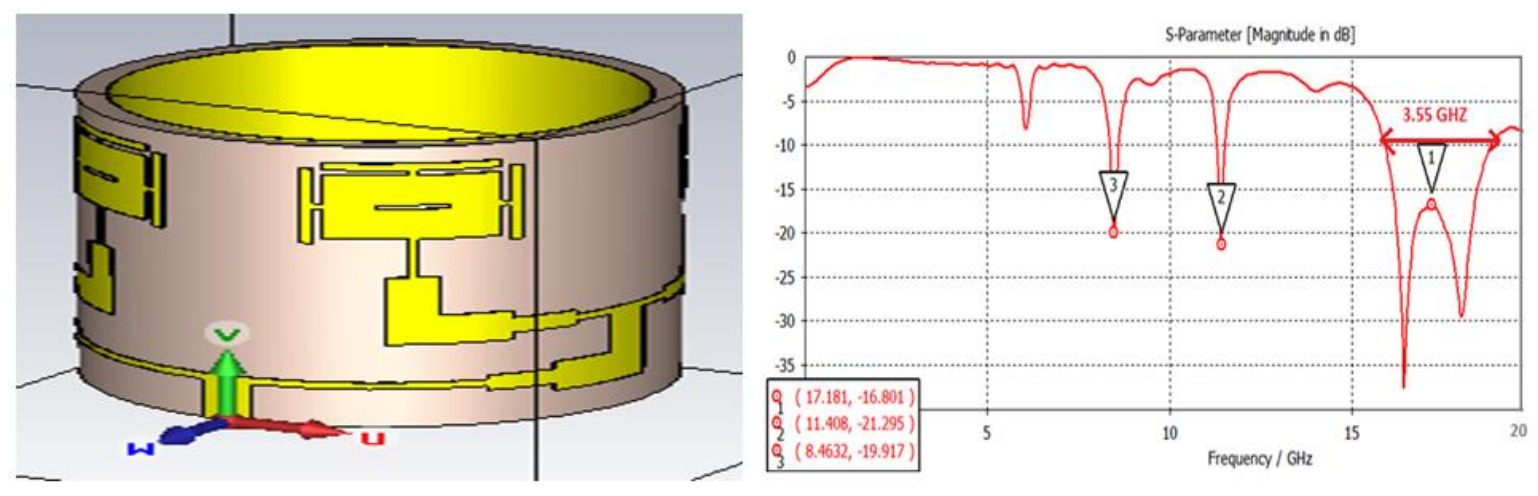

Figure 4. Model and S11-parameter conformal centre slotted antenna array

Return losses for conformal array is $-38 \mathrm{~dB}$ at $3^{\text {rd }}$ frequency. In this configuration gain/directivity improved with BW compromises. The simulated $-10 \mathrm{~dB}$ bandwidth is $3.55 \mathrm{GHz}$ and fractional bandwidth of $20 \%$.

$$
\left(f_{2}-f_{1}\right) / f_{0} \times 100=(19.3-15.75) / 17.5 \times 100=20.2 \%
$$

The radiation characteristics offered directivity of $4.3 \mathrm{~dB}$ to $6.8 \mathrm{~dB}$ of the above said frequencies in planar slotted configuration. Radiation patterns are investigated with 2-D and 3-D at $8.4 \mathrm{GHz}, 11.4 \mathrm{GHz}$ and 17.1 GHz are illustrated in Figure 5 to Figure 6 for conformal antenna array using CST software. This software is best suitable for conformal application. These radiation patterns described the main lobe magnitude, main lobe direction, angular width, radiation efficiency, total efficiency and directivity of the conformal slotted antenna array with the maximum radiation efficiency and maximum directivity of $8.2 \mathrm{db}$ and $8.5 \mathrm{~dB}$ respectively. The entire result summary is given in Table 2.

Summary of the Simulated Result- A tabular form has been made for better understanding for scattering and Radiation characteristics as show in Table 2. With reference to Figure $2 \&$ Figure 3, this proposed antenna is suitable for $\mathrm{X}$-and $\mathrm{Ku}$ band application. 
Farfedd Drectivty Abs (Phi=90)

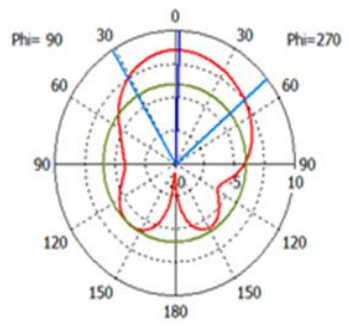

Theta / Degree vs. dB

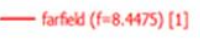

Frequency $=8.4475$

Man bbe magntude $=5.52 \mathrm{dBa}$ Man bbe drection $=2.0$ deg. Angular with $(3 \mathrm{~dB})=81.6 \mathrm{deg}$. Side lobe level $=-7.6 \mathrm{~dB}$

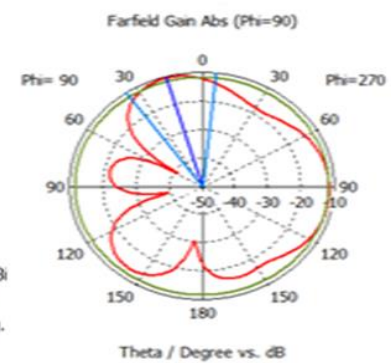

- farfed $(f=17.561)[1]$

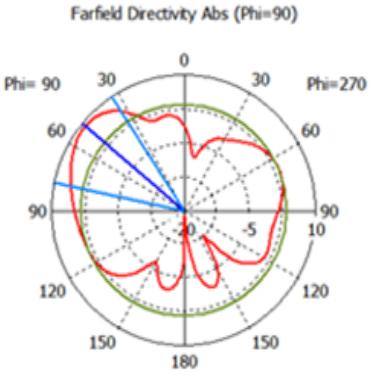

Theta / Degree vs. dB
Frequency $=17.561$ Man lobe magntude $=9.07 \mathrm{~dB}$

Man bbe drection $=50.0$ deg.

Anguar woth $(3 \mathrm{~dB})=45.0 \mathrm{deg}$.

Side labe level $=-5.6 \mathrm{~dB}$
Farfield Gain Abs (Phi=90)

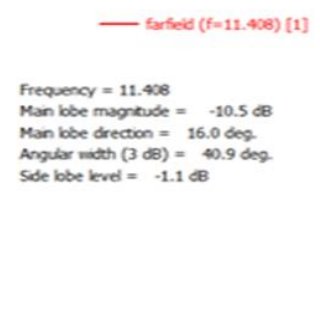

Figure 5. 2-D radiation plots for slotted conformal array at $8.4 \mathrm{GHz}, 11.4 \mathrm{GHz}$ and $17.5 \mathrm{GHz}$
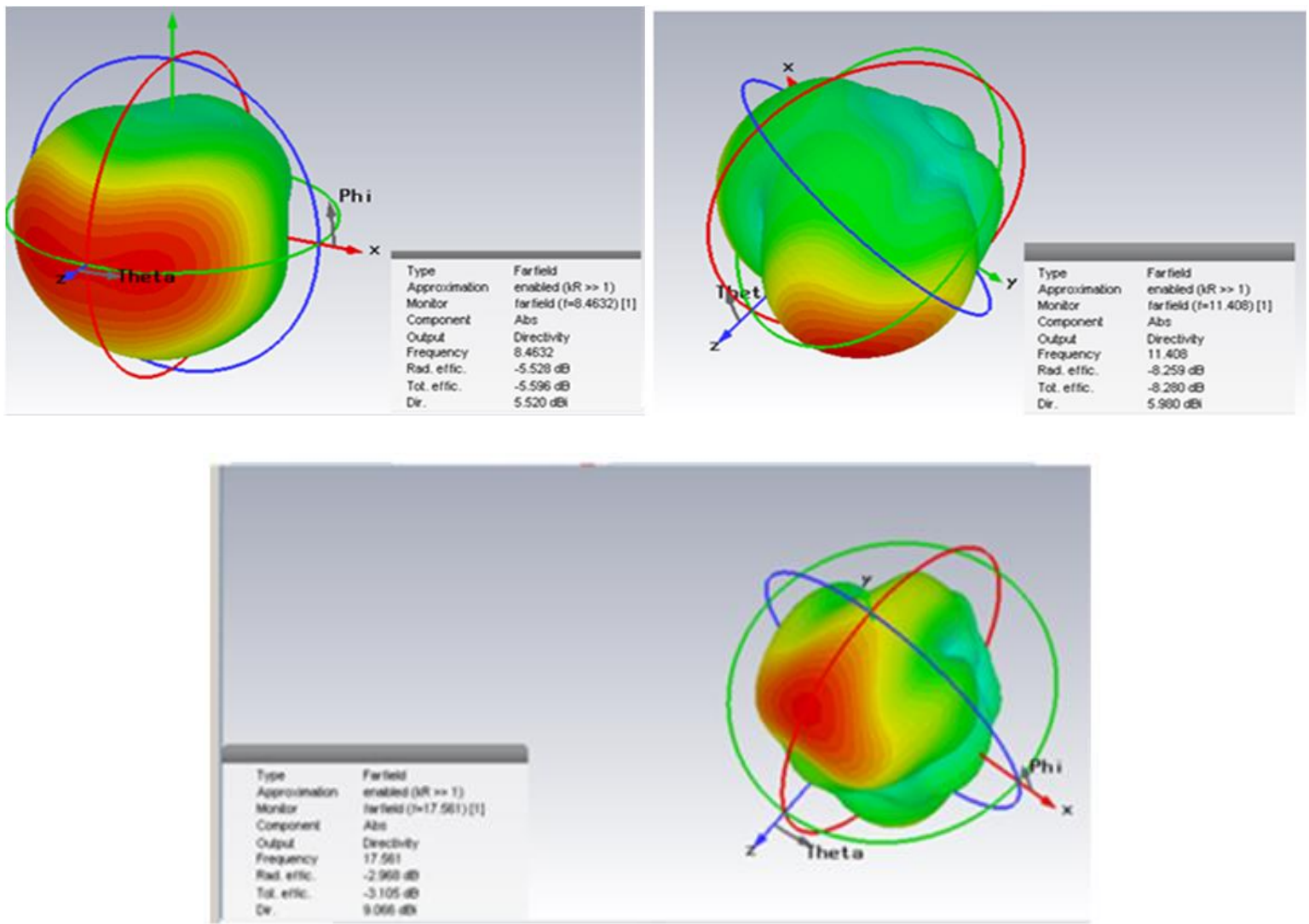

Figure 6. 3-D radiation plots for slotted conformal array at $8.4 \mathrm{GHz}, 11.4 \mathrm{GHz}$ and17.5GHz 
Table 2. Summary of the Simulated

\begin{tabular}{cccccc}
\hline SN & Freq. $(\mathrm{GHz})$ & $\mathrm{S}_{11}(\mathrm{~dB})$ & Main lobe Magnitude $(\mathrm{dB}) \&$ Direction(deg.) & Angular width (deg.) & Directivity (dBi) \\
\hline 1 & 8.4 & -20 & $5.5 \& 2$ & 81.6 & 5.5 \\
2 & 11.4 & -21 & $10.5 \& 16$ & 40.9 & 5.9 \\
3 & $\mathbf{1 7 . 1 8}$ & $\mathbf{- 1 7}$ & $\mathbf{9 . 1} \mathbf{\& ~ 5 0}$ & $\mathbf{4 5}$ & $\mathbf{9 . 2}$ \\
\hline
\end{tabular}

\section{CONCLUSION}

In this paper, an approach has been established to get the performance of conformal antenna array near to planar antenna by doing some alteration in dimensions. Fundamentally, the application of conformal antennas is suggested where good agreement has been achieved in bandwidth and the three resonating frequencies in $\mathrm{X}$ and a $\mathrm{Ku}$ band with respect to planar configuration as the performance is degrades for the curved structure. Especially on $3^{\text {rd }}$ frequency range at $15.75-19.3 \mathrm{GHz}$ with $\mathrm{S} 11$ is $-17 \mathrm{~dB}$ to- $38 \mathrm{~dB},-10 \mathrm{db} \mathrm{BW}$ $3.55 \mathrm{GHz}$, Main lobe Magnitude $9.1 \mathrm{~dB}$, Main lobe Direction $50^{\circ}$, angular width $45^{\circ}$ and directivity of $8.1 \mathrm{dBi}$ has been achieved. The main effect of the conformal surface is to increase the amplitude of cross polarization component. In order to analyze the simulation of above planar and conformal antenna array on the bases of scattering parameter, VSWR vs resonating frequencies and radiation patterns in Figures 1-6. Furthermore, a flexible substrate as RT duriode 5880 will be chosen for the fabrication purpose.

\section{ACKNOWLEDGEMENT}

I am thankful to "Jyoti Electronics" Ahmadabad for providing me the students version of CST software and also thankful to my Co guide Dr. S C Gupta, Head Antenna Lab DIT University (under DRDO project).

\section{REFERENCES}

[1] Brajlata Chauhan, Prashansha kumari, Rashmi choudary, Sandip Vijay, "Four Element Conformal Array Antenna for X-band and Ku-band applications," International Journal of Computer Science and Information Security, vol. 14, no. 5, pp. 568-576, 2016.

[2] P. Kumari, B. Chauhan, S. Vijay "Performance Analysis of Microstrip Conformal Antenna Array and Effect of Mutual Coupling for Different Curvature," International Journal of Computer applications, vol. 135, no. 9, pp. 3035, Feb 2016.

[3] E. S. Ahmed, "Conformal Band-Notch UWB Monopole Antenna on Finite Cylindrical Substrates," Engineering, Technology \& Applied Science Research ETASR, vol. 3, no. 3, pp. 440-445, 2013.

[4] S. D. Gupta, Amit Singh, "Design and Performance Analysis of Cylindrical Microstrip Antenna and Array using Conformal Mapping Technique," International Journal Of Communication Engineering Applications, vol. 2, no. 3, pp. 166-180, 2011.

[5] N. J. Kolias, R. C. Compton, J. P. Fitch, D. M. Pozar, "The Electrical Engineering Handbook," CRC Press; 2 ${ }^{\text {nd }}$ edition, 1997.

[6] Qi Wang, Qing-Qiang He, "An arbitrary conformal array pattern synthesis method that includes mutual coupling and platform effects,” Progress in Electromagnetic Research, vol. 110, pp. 297-311, 2010.

[7] N. Othman, N. A. Samsuri, M. K. A. Rahim, K. Kamardin, H. A. Majid, "Meander bowtie Antenna for Wearable Application," Telecommunication, Computing, Electronics and Control TELKOMNIKA, vol. 16, no. 4, pp. 15221526, 2018.

[8] A. Deshmukh, K. P. Ray, "Analysis of Broadband Variations of U-slot cut Rectangular Microstrip Antennas," in IEEE Antennas and Propagation Magazine, vol. 57, no. 2, pp. 181-193, April 2015.

[9] J. Chandrasekhar Rao, K. Pradeep Rajashekar, G. Prem Kumar, "H-U-E Shaped Slotted Microstrip Antenna For Bandwidth Enhancement," International Journal of Future Generation Communication and Networking," vol. 7, no. 4, pp. 141-148, 2014.

[10] J. Ghalibafan, Attari A, Farrokh Hojjat-Kashani, "A New Dual-Band Microstrip Antenna With U-Shaped Slot," Progress In Electromagnetic Research C, vol. 12, pp. 215-223, 2010.

[11] A. Khidre, K. Lee, A. Z. Elsherbeni, F. Yang, "Wide Band Dual-Beam U-Slot Microstrip Antenna," in IEEE Transactions on Antennas and Propagation, vol. 61, no. 3, pp. 1415-1418, March 2013.

[12] M. Ojaroudi, G. Ghanbari, N. Ojaroudi, C. Ghobadi, "Small Square Monopole Antenna for UWB Applications With Variable Frequency Band-Notch Function," in IEEE Antennas and Wireless Propagation Letters, vol. 8, pp. 1061-1064, 2009. [Online]. Available: https://ieeexplore.ieee.org/abstract/document/5210144.

[13] Atser A. Roy, Joseph M. Môm, Gabriel A. Igwue, "Enhancing The Bandwidth Of a Microstrip Patch Antenna Using Slots Shaped," American Journal Of Engineering Research AJER, vol. 2, no. 9, pp. 2320-0936, 2013.

[14] R. Samson Daniel, R. Pandeeswari, S. Raghavan, "A miniaturized printed monopole antenna loaded with hexagonal complementary split ring resonators for multiband operations," International Journal of RF and Microwave Computer-Aided Engineering, vol. 28, no. 7, pp. 1-8, 2018. 
[15] Mehdi Sharifi, Pejman Rezaei, "Near optimal conformal antenna array structure for direction of arrival estimation," International Journal of RF and Microwave Computer-Aided Engineering, vol. 29, no. 12, pp. 1-11, 2019.

[16] Alaa Imran Al-Muttairi, Malik Jasim Farhan, "Frequency reconfigurable monopole antenna with harmonic suppression for IoT applications," Telecommunication, Computing, Electronics and Control TELKOMNIKA, vol. 18 , no. 1 , pp. $10-18,2020$.

[17] D Biswas, V Ramachandra, "A Novel Approach To Design Conformal Frustum Wrap Around Antenna," 9th International Radar Symposium India IRSI - 13, pp. 10-14, 2013.

[18] D. H. Schaubert, F. G.Farrar, "Some Conformal Printed Circuit Antenna Designs," Proc. Workshop Printed Circuit Antenna Technology, New Mexico State Universuty Las Cruces, 1979, pp. 1-21.

[19] Pengcheng Li, Jianxin Liang, Xiaodong Chen, "Study of printed elliptical/circular slot antennas for ultrawideband applications," in IEEE Transactions on Antennas and Propagation, vol. 54, no. 6, pp. 1670-1675, June 2006.

[20] M. A. Aziz, S. Roy, L. A. Berge, Irfanullah, S. Nariyal, B. D. Braaten, "A conformal CPW folded slot antenna array printed on a Kapton substrate," 2012 6th European Conference on Antennas and Propagation EUCAP, Prague, Czech Republic, 2012, pp. 159-162.

[21] A. Negi, B. chauhan, V. Sandip, "A Microstrip Patch Antenna [pi] and T-Shaped Slot for X-Band Application," Journal IUP Journal of Telecommunications, vol. 8, no. 2, pp. 57-63, 2016.

[22] Arun Kumar Saurabh, Manoj Kumar Meshram, "Compact sub-6 GHz 5G- multiple-input -multiple output antenna system with enhanced isolation," International Journal of RF and Microwave Computer-Aided Engineering, vol. 30, no. 8, pp. 1-11, 2020. [Online]. Available: https://onlinelibrary.wiley.com/doi/abs/10.1002/mmce.22246.

[23] M. Kahrizi, T. K. Sarkar, Z. A. Maricevic, "Analysis of a wide radiating slot in the ground plane of a microstrip line," in IEEE Transactions on Microwave Theory and Techniques, vol. 41, no. 1, pp. 29-37, Jan. 1993.

[24] M. Kanno, T. Hashimura, T. Katada, M. Sato, K. Fukutani, A. Suzuki, "Digital beam forming for conformal active array antenna," Proceedings of International Symposium on Phased Array Systems and Technology, Boston, MA, USA, 1996, pp. 37-40.

[25] B. Chauhan, A. Negi, "A conformal microstrip patch antenna on cylinder back-to-back E and U shape slot for triple band operation," 2016 6th International Conference - Cloud System and Big Data Engineering (Confluence), Noida, India, 2016, pp. 670-674. 